Article

\title{
Generation and Evaluation of LAI and FPAR Products from Himawari-8 Advanced Himawari Imager (AHI) Data
}

\author{
Yepei Chen ${ }^{1,2}$, Kaimin Sun ${ }^{1, *}\left(\mathbb{C}\right.$, Chi Chen ${ }^{2}{ }^{(0}$, Ting Bai ${ }^{1,3}$, Taejin Park ${ }^{2}$, Weile Wang ${ }^{4}$, \\ Ramakrishna R. Nemani ${ }^{4}$ and Ranga B. Myneni ${ }^{2}$ \\ 1 State Key Laboratory of Information Engineering in Surveying, Mapping and Remote Sensing, \\ Wuhan University, Wuhan 430079, China \\ 2 Department of Earth and Environment, Boston University, Boston, MA 02215, USA \\ 3 Department of Geography, University at Buffalo, The State University of New York, Buffalo, NY 14261, USA \\ 4 NASA Ames Research Center, Moffett Field, CA 94035, USA \\ * Correspondence: sunkm@whu.edu.cn; Tel.: +86-180-4058-5690
}

Received: 28 May 2019; Accepted: 24 June 2019; Published: 27 June 2019

check for updates

\begin{abstract}
Leaf area index (LAI) and fraction of photosynthetically active radiation (FPAR) absorbed by vegetation are two of the essential biophysical variables used in most global models of climate, hydrology, biogeochemistry, and ecology. Most LAI/FPAR products are retrieved from non-geostationary satellite observations. Long revisit times and cloud/cloud shadow contamination lead to temporal and spatial gaps in such LAI/FPAR products. For more effective use in monitoring of vegetation phenology, climate change impacts, disaster trend etc., in a timely manner, it is critical to generate LAI/FPAR with less cloud/cloud shadow contamination and at higher temporal resolution-something that is feasible with geostationary satellite data. In this paper, we estimate the geostationary Himawari-8 Advanced Himawari Imager (AHI) LAI/FPAR fields by training artificial neural networks (ANNs) with Himawari-8 normalized difference vegetation index (NDVI) and moderate resolution imaging spectroradiometer (MODIS) LAI/FPAR products for each biome type. Daily cycles of the estimated AHI LAI/FPAR products indicate that these are stable at 10-min frequency during the day. Comprehensive evaluations were carried out for the different biome types at different spatial and temporal scales by utilizing the MODIS LAI/FPAR products and the available field measurements. These suggest that the generated Himawari-8 AHI LAI/FPAR fields were spatially and temporally consistent with the benchmark MODIS LAI/FPAR products. We also evaluated the AHI LAI/FPAR products for their potential to accurately monitor the vegetation phenology-the results show that AHI LAI/FPAR products closely match the phenological development captured by the MODIS products.
\end{abstract}

Keywords: Leaf area index (LAI); fraction of photosynthetically active radiation (FPAR); artificial neural networks (ANNs); Himawari-8 Advanced Himawari Imager (AHI); normalized difference vegetation index (NDVI); moderate resolution imaging spectroradiometer (MODIS)

\section{Introduction}

Leaf area index (LAI), defined as one-sided green leaf area per unit ground area in broadleaf canopies and as the projected needle leaf area in coniferous canopies [1,2], characterizes the vegetation structure and functioning [3]. Fraction of photosynthetically active radiation (FPAR) measures the fraction of radiation absorbed by the green vegetation in the $400 \sim 700 \mathrm{~nm}$ spectrum under specified illumination conditions [4,5], and hence, characterizes the energy absorption capacity of a canopy. 
Therefore, LAI and FPAR are the two key variables in most climatic, hydrological, biogeochemical, and ecological models [6-9].

Over the past decades, a number of LAI/FPAR products have been successfully developed from satellite data, such as coarse-resolution products for the moderate resolution imaging spectroradiometer (MODIS) [10-12], Visible Infrared Imaging Radiometer Suite (VIIRS) [13-15], and SPOT-Vegetation [16-18], fine-resolution retrievals from Sentinel-2 [19,20], Landsat [21,22], and downscaling products combining coarse-resolution and fine-resolution data [23-25]. All of these products were generated from non-geostationary satellite observations. As a result of relatively long revisit times and potential/residual cloud and cloud shadow contamination, these products are not spatially and temporally continuous. Fortunately, current geostationary satellites provide an opportunity to generate consistent LAI/FPAR at much higher temporal frequency and with many more cloud-free observations.

Himawari-8, a new generation Japanese geostationary Earth orbit meteorological satellite, was successfully launched by the Japan Meteorological Agency (JMA) on 7 October, 2014. Advanced Himawari Imager (AHI) on-board Himawari-8 has 16 observation bands at 0.5 or $1 \mathrm{~km}$ for visible and near-infrared bands and $2 \mathrm{~km}$ for infrared bands, providing images covering the East Asia-Western Pacific region [26]. The Himawari-8 AHI is an advanced sensor in terms of the number of bands, spatial resolution, and temporal frequency compared to previous geostationary sensors (e.g., IMAGER onboard Himawari-7). Most of all, the shortened revisit times are around $10 \mathrm{~min}$ for full disk (images of the whole Earth as seen from the satellites) and $2.5 \mathrm{~min}$ for Japan and target areas [27]. With these advantages, Himawari-8 AHI can provide a new level of capacity for numerical weather prediction, disaster and environmental monitoring [28].

For effective use in monitoring of vegetation phenology, climate change impacts, and disaster trends etc., in a timely manner, it is valuable to generate geostationary satellite-based LAI/FPAR products. Physical methods based on radiative transfer theory were widely used to generate LAI/FPAR products due to the high accuracy $[2,12,14]$. However, the methods need several biophysical variables and are computationally intensive for operational use. Machine learning algorithms are increasingly being used lately to mimic the underlying physical processes because they are simple, fast, and require low computer resources once the learning phase is achieved $[17,29,30]$. The efficacy of the machine learning approaches depends on the robustness and availability of the training data. Taking the advantage of MODIS LAI/FPAR products with high confidence and AHI normalized difference vegetation index (NDVI) product with significant increase in cloud-free observation, machine learning is a good way to quickly and accurately generate AHI LAI/FPAR products based on the relationship between LAI/FPAR and NDVI.

In this paper, artificial neural networks (ANNs) were utilized to estimate AHI LAI/FPAR products from biome-specific LAI/FPAR-NDVI relationships. This method is simple and computationally efficient, as there is no need of complex models and biophysical variables. In addition, ANNs have been successfully used to generate AVHRR LAI/FPAR products with MODIS LAI/FPAR and AVHRR NDVI as the training inputs [17]. We used 16-day composited MODIS LAI/FPAR climatology over 2011 to 2017 as a benchmark to derive the relationships between LAI/FPAR and NDVI for each of the biome type representatives of global vegetation. For every 16 days, a biome-specific artificial neural network was trained over Himawari-8 AHI NDVI, MODIS LAI/FPAR with MODIS land cover data constraining the biome space, after which daily LAI/FPAR products were estimated with the artificial neural network. The AHI LAI/FAPR products at 10-min frequency during daytime were also generated to assess the stability with respect to the illumination angle. The retrieved LAI/FPAR products were compared to the reference MODIS LAI/FPAR products for spatial and temporal consistency. We also evaluated the AHI LAI/FPAR products for monitoring vegetation phenology by utilizing MODIS LAI/FPAR and vegetation index products.

This paper is organized as follows: Section 2 describes the data sets used in this study. Section 3 introduces the methods for estimating AHI LAI/FPAR production and their evaluation. The evaluation 
results of AHI products are presented and analyzed in Section 4. Finally, concluding remarks are provided in Section 5.

\section{Materials}

\subsection{AHI NDVI Products}

Himawari-8 AHI NDVI data from the GEONEX (Geostationary-NASA Earth Exchange) land-monitoring products are used in this study. For AHI, the GEONEX processing starts with the 10-min full-disk Himawari Standard Data (HSD) as the input, which are Level 1b top-of-atmosphere (TOA) radiance data that are radiometrically calibrated and geometrically registered to a regular grid in the geostationary (or fixed-point) projection [31,32]. The processing pipeline checks and corrects residue geolocation errors of the input data, computes the satellite viewing angles (static) and the solar illuminating angles (every time step) for each grid point, and converts the radiances to TOA bidirectional reflectance factor for the reflective bands (bands 1 to 6 ) and brightness temperature for the emissive bands (bands 7 to 16). It then re-projects the data onto a regular grid in the geographic projection $\left(60^{\circ} \mathrm{N}-60^{\circ} \mathrm{S}, 84^{\circ} \mathrm{W}-204^{\circ} \mathrm{E}\right.$ for $\mathrm{AHI}$ ) at spatial resolutions of $0.005^{\circ}$ (band 3), $0.01^{\circ}$ (bands 1 , $2,4)$, and $0.02^{\circ}$ (the rest bands). The AHI grid is part of a global grid system $\left(60^{\circ} \mathrm{N}-60^{\circ} \mathrm{S}, 180^{\circ} \mathrm{W}-180^{\circ} \mathrm{E}\right)$ that is divided in $6^{\circ} \times 6^{\circ}$ tiles and numbered from $0\left(60^{\circ} \mathrm{N}\right.$, upper bound) to $19\left(54^{\circ} \mathrm{S}\right.$, upper bound) in the vertical direction and from $0\left(180^{\circ} \mathrm{W}\right.$, left bound) to $59\left(174^{\circ} \mathrm{E}\right.$, left bound) in the horizontal direction. Thus, the spatial domain of AHI spans horizontally from tile 44, crossing tile 59, onto tile 4 .

In the next step, the GEONEX processing pipeline runs a customized version of the NASA MAIAC (multi-angle implementation of atmospheric correction) algorithm [33-35] to screen clouds and cloud shadows, retrieve aerosol optical thickness, and remove the influence of atmospheric absorption and scattering from the TOA data to produce surface reflectance (BRF) for the reflective bands (bands 1-6). The MAIAC algorithm explicitly considers the influences of surface bidirectional reflectance properties on the TOA reflectance measured by satellite sensors. It thus has the advantages to exploit the high temporal frequency and the multi-solar-angle observations featured by the geostationary sensors. The version of MAIAC used in this study is based on the latest MODIS Collection 6 code [35], with new lookup tables (LUTs) and retrieve algorithms particularly tailored according to AHI spectral bands to produce high quality surface BRF data.

Lastly, we calculated NDVI using the atmospherically corrected BRFs from the red (band 3) and the near infrared (NIR; band 4) channels at every 10-min steps. The red band BRFs are averaged to the $0.01^{\circ}$ resolution to match with the NIR band. We then composited the NDVI values at daily, 4-day, and 16-day time windows based on the following quality control criteria: (1) Only the BRF retrieved with clear atmosphere conditions and low aerosol loadings are selected for composition, while cloudy/shadowy pixels are discarded; (2) retrievals with lower solar zenith angles (close to local noon) are given higher priority in the compositing process. Retrievals with solar zenith angles above $65^{\circ}$ are discarded; (3) higher NDVI values are favored in the compositing process if the aforementioned two criteria are satisfied. In addition, we also examined the product of NDVI and the NIR reflectance [36] as a measure to filter suspicious high NDVI values (e.g., caused by residual cloud shadows). The results are considered the best estimate of NDVI over the compositing period.

In this study, the quality controlled 16-day and daily AHI NDVI composites during 2016-2017 over the AHI domain (full disk) were used to generate training data and estimate AHI LAI/FPAR products.

\subsection{MODIS Biome Map}

A biome map is an important input to train the ANNs for the estimation of LAI/FPAR. The map is used as a priori information to constrain the training biome space. MODIS land cover (MCD12Q1, layer 3) products from the latest version Collection 6 (C6) are used in this study [37]. The Terra and Aqua combined land cover yearly product MCD12Q1 is at 500 meters spatial resolution and the land cover type 3 classifies the global vegetation into eight biomes: grasses and cereal crops (biome 1), 
shrubs (biome 2), broadleaf crops (biome 3), savannahs (biome 4), evergreen broadleaf forests (biome 5), deciduous broadleaf forests (biome 6), evergreen needleleaf forests (biome 7), and deciduous needleleaf forests (biome 8).

To match the spatial scale of Himawari-8 AHI for the training of ANNs and estimation of AHI LAI/FPAR, MODIS biome map was re-projected to the same grid of AHI data and resampled to $0.01^{\circ}$ pixel size by using the most occupied biome type within every four pixels.

\subsection{MODIS C6 LAI/FPAR Product}

During the past decades, the series of MODIS LAI/FPAR products have been widely used in extensive studies of the land surface and climate modelling [38-42]. The latest Collection 6 (C6) of MODIS LAI/FPAR products was released in 2015. These have been comprehensively evaluated with other data sets and validated with ground measurements, giving confidence on their accuracy and consistency with other existing LAI/FPAR products [43-48]. The C6 LAI/FPAR product provides LAI/FPAR retrievals at 500 meters pixel size from Terra MODIS (morning overpass), Aqua MODIS (afternoon overpass), and Terra MODIS + Aqua MODIS combined. There are two types of temporal compositing periods for these products, 8 days and 4 days. Considering the AHI raw data are obtained in 10-min interval during the daytime, the Terra and Aqua combined 4-day composited LAI/PFAR product (MCD15A3H) is used in this study as a benchmark to train ANNs and evaluate AHI estimates [49].

The MCD15A3H LAI/FPAR product is a 4-day composite with a pixel size of 500 meters. The algorithm chooses the "best" pixel available from all the acquisitions of both MODIS sensors located on NASA's Terra and Aqua satellites within the 4-day period. The MCD15A3H product has six science data sets (SDS): (1) Fpar; (2) Lai; (3) FparLai_QC; (4) FparExtra_QC; (5) FparStdDev; (6) LaiStdDev. The first and second SDS are FPAR and LAI retrievals respectively, and the last two SDS are the standard deviation of respective FPAR and LAI candidates. The quality control (QC) data are contained in the third and fourth SDS to indicate the algorithm path (i.e., main algorithm and back-up algorithm) and contamination (i.e., cloud, cloud shadow, and snow, etc.).

In this study, the MODIS LAI/FPAR products are reprocessed by selecting the good quality observations retrieved by the main algorithm and without contamination based on the QC layers. The MODIS LAI/FPAR products in sinusoidal projection system are re-projected to the same grid of AHI data and resampled to $0.01^{\circ}$ pixel size. To create stable ANNs, climatology of LAI/FPAR is produced during 2011-2017 over the AHI domain to train ANNs. The 4-day and 8-day composite MODIS LAI/FPAR products also perform as reference LAI/FPAR fields to evaluate the estimated AHI LAI/FPAR.

\subsection{MODIS C6 Vegetation Index Product}

To evaluate the capability of AHI LAI/FPAR to capture the vegetation phenology, MODIS C6 vegetation index product (MOD13A2) was used in this study as reference [50]. The MOD13A2 Version 6 product provides 16-day composited vegetation index (VI) values on a per pixel basis at $1 \mathrm{~km}$ spatial resolution. There are two primary vegetation index layers: The first is the normalized difference vegetation index (NDVI); the second is the enhanced vegetation index (EVI), which has improved sensitivity over high biomass regions. The algorithm for this product chooses the best available pixel value from all the acquisitions from the 16-day period. The criteria used are low clouds, low view angle, and the highest NDVI/EVI value.

Provided along with the vegetation index layers, there is a quality assurance (QA) layer indicating the quality and the absence of contamination. In this study, MODIS NDVI and EVI layers were reprocessed using the QA flags to mask out pixels with bad quality and contamination, and then re-projected to the same grid of $\mathrm{AHI}$ data and resampled to $0.01^{\circ}$ pixel size. 


\subsection{Field Sites}

To analyze the uncertainty between AHI LAI/FPAR and ground measurements, we synthesized all available field-measured LAI/FPAR data over the AHI domain $\left(60^{\circ} \mathrm{S}-60^{\circ} \mathrm{N}, 84^{\circ} \mathrm{W}-204^{\circ} \mathrm{E}\right)$ by investigating DIRECT dataset and literatures. DIRECT is a collection of sites for which ground measurements are available [3]. Values of measured variable (leaf area index, FAPAR, FCOVER) are provided as an average value over the $3 \mathrm{~km} \times 3 \mathrm{~km}$ area represented by the site. The latest version DIRECT 2.0 filters forest sites with no understory and expands the time series of up to 2017 with the inclusion of more than 60 new sites (coming from FP7 ImagineS, ESA and EOLAB campaigns). DIRECT 2.0 contains 140 sites and 242 samples during the 2000-2017 period. However, there are no field measurements for the Himawari-8 AHI era (2016-present). Therefore, MODIS LAI in 2012-2013 and in 2016-2017 was utilized as the intermediary between AHI LAI in 2016-2017 and field measured LAI in 2012-2013.

There were three different field campaigns over the full disk of AHI, and those include ImagineS [51], Heihe Watershed Allied Telemetry Experimental (HiWater) [22], and Huailai [52]. The ImagineS project has conducted a series of single date or multi-temporal field campaigns over 23 sites around the world during the 2013-2016 period (http://fp7-imagines.eu). The ground measurements have been processed according to the Committee of Earth Observation Satellites (CEOS) Land Products Validation (LPV) subgroup guidelines [53]. The observation program HiWater for the Heihe River basin were performed from 2008 to 2013 [54]. A $3 \mathrm{~km} \times 3 \mathrm{~km}$ agricultural area in the Heihe River basin, Gansu province, China $\left(38^{\circ} 51^{\prime} \mathrm{N}, 100^{\circ} 21^{\prime} \mathrm{E}\right)$ is selected as the field site. The Huailai remote sensing experimental station $\left(40^{\circ} 22^{\prime} \mathrm{N}, 115^{\circ} 46^{\prime} \mathrm{E}\right)$ in Beijing, China is also an agricultural site. Corn is the dominant crop in the Hebei and Huailai sites. The ground measurements are scaled-up using a high resolution imagery (ASTER) and a sampling strategy (sampling based on priori information), which are later aggregated to the moderate resolution products. These site-specific LAI/FPAR data are average values over $3 \mathrm{~km} \times 3 \mathrm{~km}$ area which have been used in a number of previous studies to validate LAI/FPAR products $[12,29,46,47]$.

\section{Methods}

\subsection{Estimation of AHI LAI/FPAR Using ANN}

A number of studies on various vegetation types have led to the general conclusion that spectral vegetation indices may be considerably sensitive to LAI/FPAR changes [55-58]. The normalized difference vegetation index (NDVI) is one of the most extensively used vegetation indices related to LAI/FPAR [57]. Approaches based on relationships between LAI/FPAR and spectral vegetation indices are easier to implement operationally and more efficient than physical methods because ancillary parameters and complex models are not required. The relationship between NDVI and LAI is nonlinear and exhibits considerable variation among the sites, time, and cover types [57,59]. Thus, ANNs, which are able to simulate nonlinear issues [60], were used to generate AHI LAI/FPAR for different biome types.

ANN are widely used in remote sensing and quantitative analysis because of good predictably and relevance $[30,60]$. In this study, we used the feed-forward neural network (FFNN) to estimate AHI LAI/FPAR data sets. The FFNN models consisted of four neurons in the input layer (the AHI NDVI, biome type, pixel-center latitude, and pixel-center longitude), 11 neurons in the hidden layer, and 1 neuron in the output layer (LAI or FPAR). The FFNNs were trained through the back-propagation process, which is one of the most popular and widely used methods to train neural networks for its parallel processing, non-linear nature, and self-learning characteristics [61,62]. Figure 1 shows the process of generating AHI LAI/FPAR products. A FFNN model was generated for each 16-day period with 16-day composite LAI/FPAR climatology from MODIS and 16-day composite NDVI from AHI. Daily AHI LAI/FPAR was then estimated from AHI daily NDVI using the corresponding networks. 


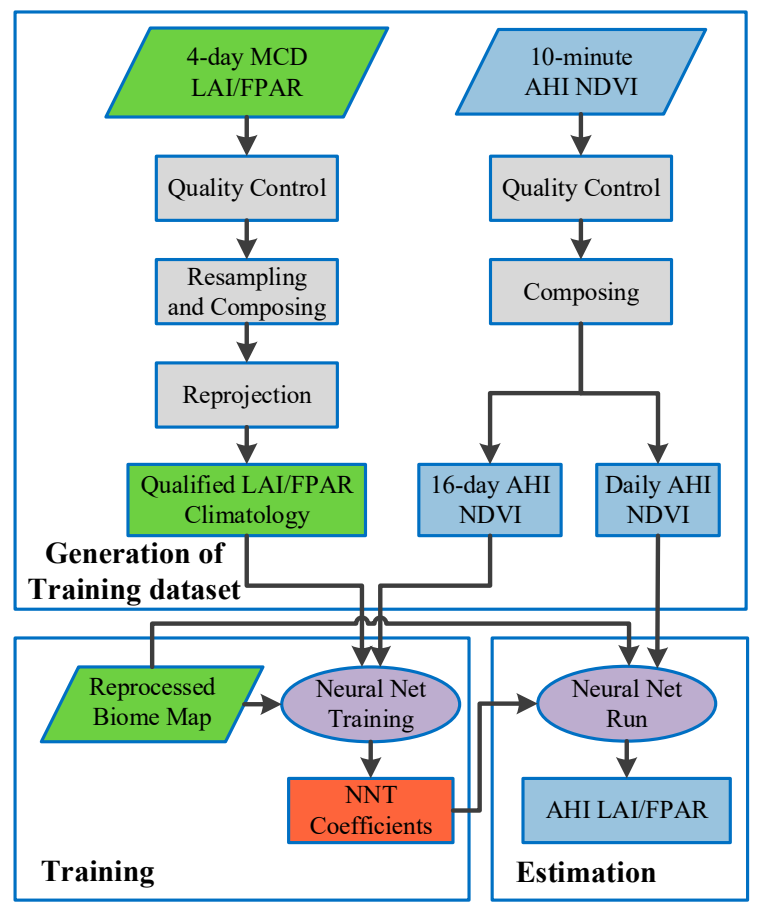

Figure 1. Flow chart of generating Advanced Himawari Imager (AHI) leaf area index/fraction of photosynthetically active radiation (LAI/FPAR) products.

\subsection{Comparison between AHI and MODIS Products}

In this study, AHI LAI/FPAR and MODIS LAI/FPAR are compared to assess their spatial and temporal consistency. We evaluated the spatial consistency between the AHI and MODIS products at global and zonal scales, and the temporal consistency was evaluated at 4-day and seasonal scales, respectively. To compare AHI and MODIS products reasonably, several issues need to be addressed. First, the different geometrical characteristics caused by discrepancies in uncertainty of geolocation, point spread function (PSF), spatial resolution and projection system should be considered because the comparison needs to be performed over the same area [63]. Thus, the MODIS products were re-projected to the same grid of AHI data and resampled to $0.01^{\circ}$ pixel size. Studies suggested that it is an effective way to reduce potential geolocation errors and PSF impacts by comparing products over a much larger area than their native spatial resolution [3]. To address this issue, we compare AHI LAI/FPAR and MODIS LAI/FPAR over a $3 \mathrm{~km} \times 3 \mathrm{~km}$ area at site scale as proposed by the CEOS LPV subgroup guidelines [53]. Quality control is the second issue that should be considered. For both AHI and MODIS products, quality control was performed to mask out pixels contaminated by clouds, cloud shadow, cirrus, and snow. Only retrievals from the main algorithm were used in our study due to the low accuracy of back-up algorithm retrievals. Figure S2 details the selection of valid pixels from MODIS products based on "FparLai_QC" and "FparExtra_QC" layers. In addition, the biome classification map (see Figure S1) was used to identify vegetated pixels and the specific vegetation type when spatially and temporally comparing the AHI and MODIS products. A series of statistical metrics (mean, standard deviation (std.), root mean square error (RMSE), and coefficient of determination $\left(R^{2}\right)$ ) were used to quantify the difference between AHI and MODIS products.

\subsection{Site Selection}

In our study, field sites were selected to validate AHI LAI/FPAR. The potential of AHI products to capture phenology was evaluated over deciduous broadleaf forests sites. In order to reduce unexpected errors from land surface heterogeneity, a criterion termed information entropy [46] was adopted to select sites with a homogeneous land surface condition. The information entropy $(E)$ is defined as follows: 


$$
E=-\sum_{i=1}^{11}\left(P_{i} \times \log _{2} P_{i}\right),
$$

where $i$ represents the specific biome type from MODIS land cover product, $P_{i}$ is the proportion of the area covered by the $i$-th biome type (note that if a biome type is not present at the site $\left(P_{i}=0\right)$, its contribution to the entropy is simply zero). The value 11 corresponds to the total number of MODIS land cover types. We selected the sites if the $E$ of a site was below 1 .

\section{Results}

\subsection{Daily Cycle}

We adopted ANNs to estimate the daily AHI LAI/FPAR. To evaluate the AHI products in a daily cycle, the AHI LAI/FPAR and NDVI are presented in a 10-min interval during the daytime, as shown in Figure 2. We selected three sites for different biomes (shrubs, evergreen broadleaf forests, and deciduous broadleaf forests) on three separate days in 2017 to analyze the daily cycle. As the sites are in different time zones, the universal time-Greenwich Mean Time (UTC/GMT)—was used. Figure 2 shows a stable pattern for both LAI/FPAR and NDVI aggregated on different sites at different dates. The results demonstrate that reliable daily NDVI can be composited from the raw data at a 10-min frequency, which will contribute to the estimation of good-quality LAI/FPAR.
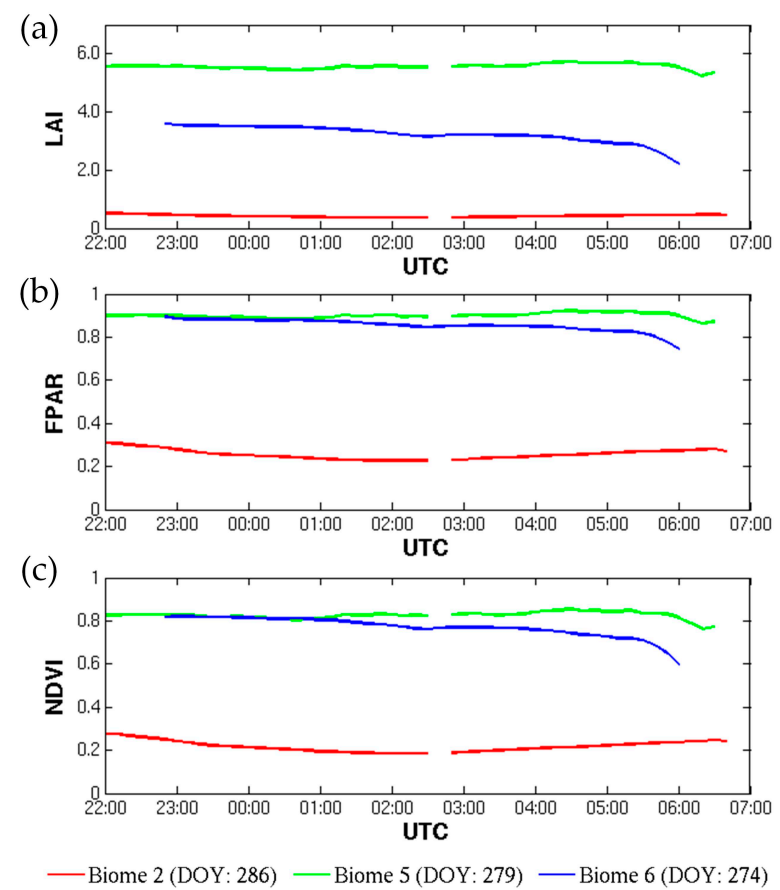

Figure 2. Daily cycle for three biome types on different days of 2017: (a) LAI; (b) FPAR; (c) normalized difference vegetation index (NDVI).

\subsection{Comparison with MODIS LAI/FPAR}

We generated AHI daily LAI/FPAR over the AHI domain from 2016 to 2017 using ANNs trained with MODIS LAI/FPAR and AHI NDVI. MODIS LAI/FPAR was used as the reference data to evaluate the estimated AHI LAI/PFAR in terms of both spatial and temporal consistency.

\subsubsection{Spatial Consistency}

The spatial patterns of LAI from AHI and MODIS and the difference between them over the AHI domain during the summer (13-20 August) of 2017 are presented in Figure 3, while Figure 4 depicts the patterns of FPAR. There are fewer gaps (no-data pixels) in AHI LAI/FPAR maps than those in MODIS 
LAI/FPAR maps (the missing data rate is $10.83 \%$ for AHI LAI/FPAR, but up to $26.77 \%$ for MODIS LAI/FPAR). It suggests that AHI provides more clear observations with much less contamination, which will contribute to monitoring vegetation phenology, disaster trends, etc. This benefits from the high temporal resolution of AHI.

(a)

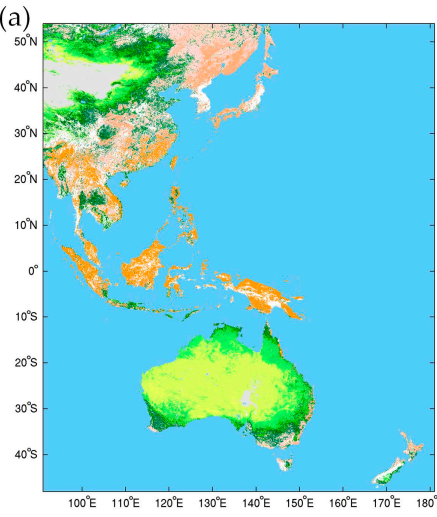

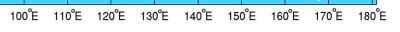

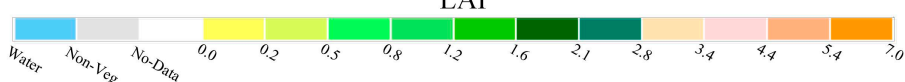

(b)

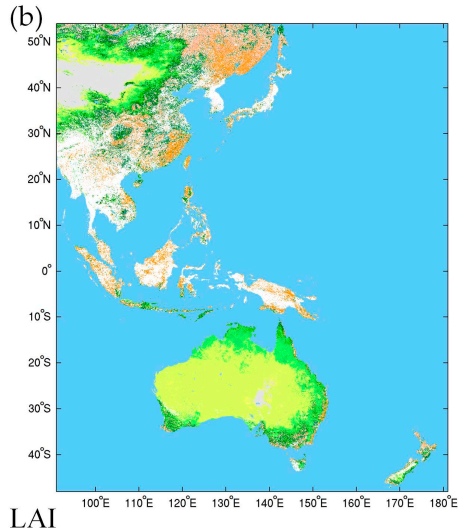

$\begin{array}{llllllll}1.6 & 2.1 & 2.8 & 3.4 & 4.8 & 5.4 & ? .0\end{array}$

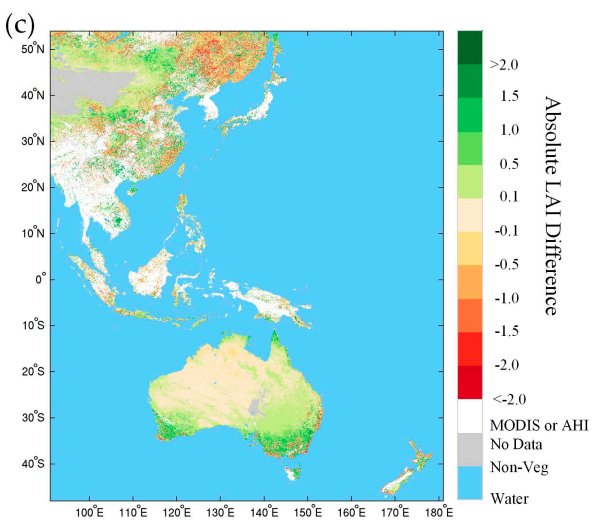

Difference (AHI - MODIS)

Figure 3. Comparison of spatial distributions of LAI from AHI and moderate resolution imaging spectroradiometer (MODIS) products over the whole AHI domain during the summer (13-20 August) of year 2017: (a) AHI LAI; (b) MODIS LAI; (c) LAI difference between AHI and MODIS. No-data pixels in white color are observations contaminated by cloud, cloud shadow, aerosol, etc. The missing data rate of AHI LAI (10.83\%) is much lower than that of MODIS LAI (26.77\%) benefiting from more frequent observations.
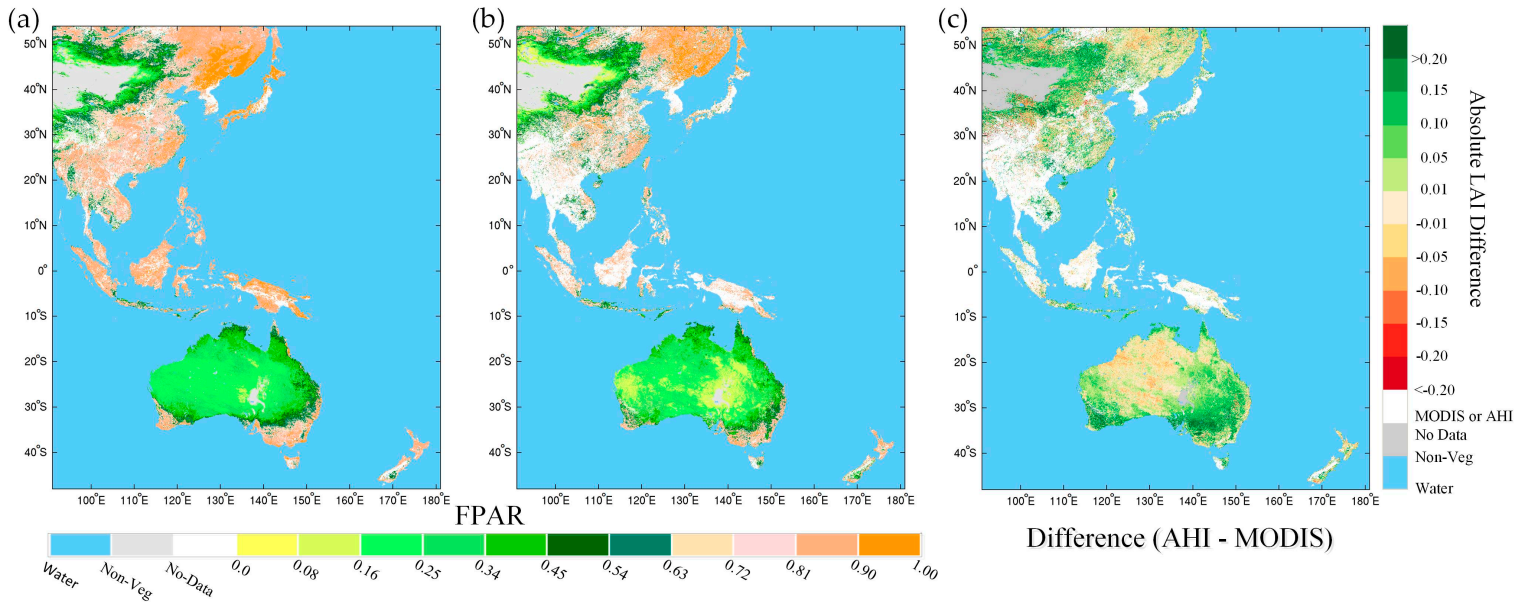

Figure 4. Comparison of spatial distributions of FPAR from AHI and MODIS products over the whole AHI domain during the summer (13-20 August) of year 2017: (a) AHI FPAR; (b) MODIS FPAR; (c) FPAR difference between AHI and MODIS. No-data pixels in white color are observations contaminated by cloud, cloud shadow, aerosol, etc. The missing data rate of AHI FPAR (10.83\%) is much lower than that of MODIS FPAR (26.77\%) benefiting from more frequent observations.

For both AHI and MODIS, LAI and FPAR show similar distribution patterns. The LAI/FPAR pattern closely corresponds with the distribution of biome types-high LAI/FPAR values over forests and low values over non-forest vegetated areas. Figure $3 a, b$ and Figure $4 a, b$ show that the LAI/FPAR values are high (up to 7 for LAI and up to 1 for FPAR) over tropical evergreen forests (i.e., Indonesia rain forests) but low over bare lands, grasslands, and shrublands (i.e., Northwestern China and Australia).

The valid AHI LAI (Figure 3a) and MODIS LAI (Figure 3b) show very similar spatial distributions. The differences between LAI values from AHI and MODIS shown in Figure $3 c$ are mostly within 
a small range $( \pm 0.5)$. Therefore, the difference map suggests no systematic bias between AHI LAI and MODIS LAI. Larger LAI differences (underestimation) appear in high LAI domains, while smaller differences are located at relatively low LAI values. This is due to the low correlation between NDVI and LAI in the case of deciduous canopies because of the fact that large LAI saturates the NDVI [64]. As it is asserted in a previous study, for a pure forest pixel, NDVI values reach a maximum of 0.8 for LAI near 3 and greater LAIs are not distinguishable with NDVI data [65]. Similar spatial patterns of FPAR from AHI and MODIS and the difference map between them are shown in Figure 4 . The AHI FPAR values agree well with MODIS FPAR with small differences (mostly within \pm 0.10 ) between them. The FPAR difference map (Figure 4c) between AHI and MODIS shows much less underestimation in high domain than LAI difference (Figure 3c). This can be explained by the fact that FPAR is linearly proportional to NDVI without saturation, while LAI is nonlinearly connected to NDVI with saturation in high domain (Figure S3).

To detail the differences between AHI and MODIS LAI/FPAR products, the histograms of LAI/FPAR differences as well as the respective means and standard deviations are shown in Figure 5. The histograms of LAI/FPAR differences demonstrate good consistency between AHI and MODIS, as more than $90 \%$ of LAI differences are within the range from -0.1 to 0.35 , and more than $85 \%$ of FPAR differences are between -0.06 to 0.14 . The statistics show that the AHI and MODIS LAI/FPAR products agree well as the mean difference across all biomes is 0.0973 for LAI and 0.0481 for FPAR. A large LAI discrepancy is observed in four forest biomes (biomes 5-8), which is probably because of the saturation issue in dense vegetation canopies [47].

(a)

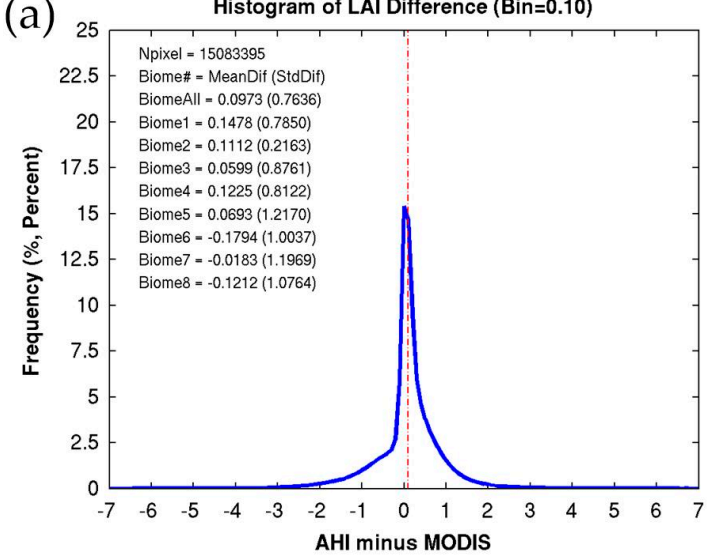

(b)

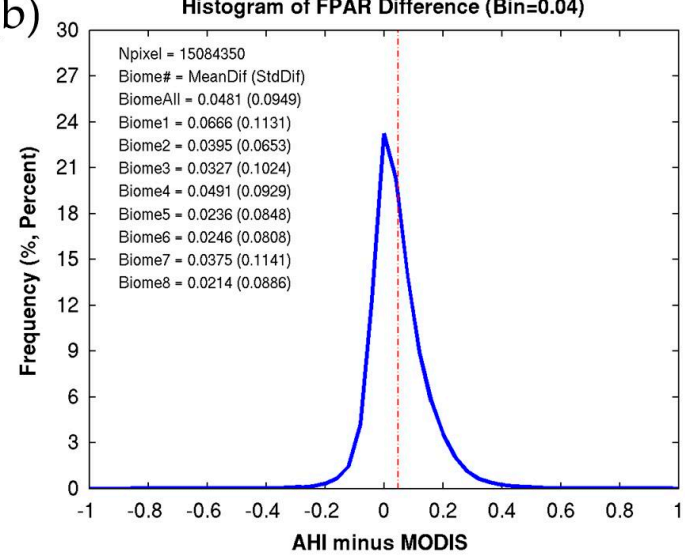

Figure 5. Histogram depicting LAI/FPAR comparison between AHI and MODIS over the whole domain during the summer (13-20 August) of year 2017: (a) LAI; (b) FPAR.

The AHI and MODIS LAI/FPAR products are further compared for specific biome types. Figures 6 and 7 depict the density scatter plots for LAI and FPAR 8-day composites during the summer (13-20 August) of year 2017. The eight biome types are grouped into three broad categories (biomes 1-4: non-forest; biomes 5-6: broadleaf forests; biomes 7-8: needleleaf forests). The $R^{2}$, RMSE, and regression equations are also provided. For all biomes (Figures 6a and 7a), a good consistency is seen for both LAI and FPAR estimates, as the density scatters are distributed along the 1:1 line with $R^{2}$ values of 0.840 for LAL and 0.881 for FPAR, and RMSE values of 0.681 for LAI and 0.090 for FPAR. The comparison between AHI and PROBA-V LAI/FPAR products for all biomes also show a good agreement (Figure S4). From Figure $6 \mathrm{~b}-\mathrm{d}$, we can see that the forest biomes (biomes 5-6 and biomes 7-8) show underestimation (mean AHI LAI is lower than mean MODIS LAI), and non-forest biomes show better agreement between AHI and MODIS than forest biomes (biomes 5-6 and biomes 7-8) for LAI, since $R^{2}$ value for non-forest biomes (0.766) is much higher than that for forest biomes $(0.270$ for biomes $5-6$ and 0.238 biomes 7-8) and RMSE value for non-forest biomes (0.563) is lower than that for forest biomes ( 0.678 for biomes $5-6$ and 0.631 biomes $7-8)$. This conclusion is also consistent with the spatial patterns 
of LAI/FPAR in Figure 3c. Not surprisingly, this is partially due to the reflectance saturation in dense vegetation canopies. For FPAR (Figure $7 b-d$ ), the statistical information shows a different trend. Overestimation is observed for both non-forest and forest biomes and there is no saturation in high domain because FPAR is lineally connected to NDVI (Figure S3).

$$
\text { (a) }
$$

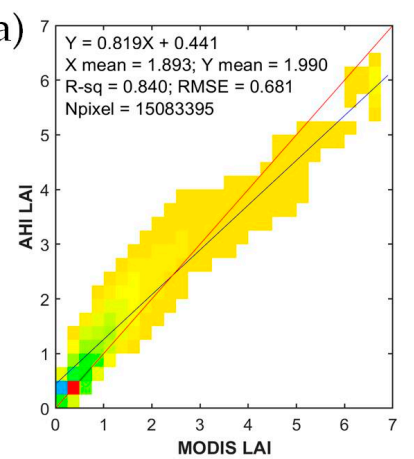

(c)

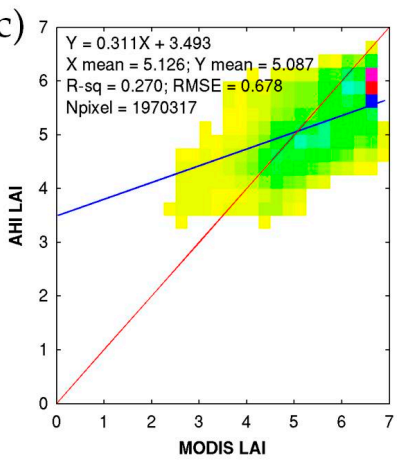

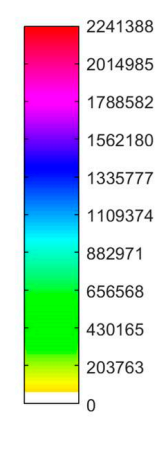

(b)

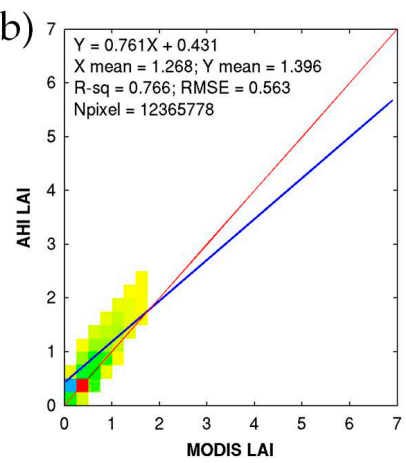

(d) 7

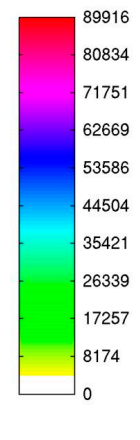

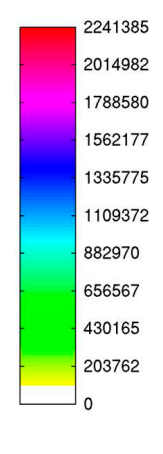

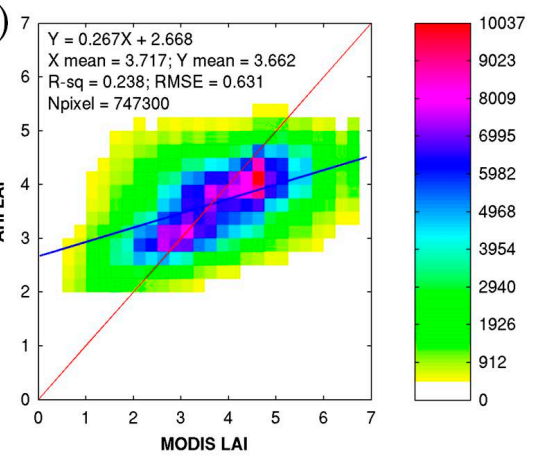

Figure 6. Density scatter plots of biome-specific AHI and MODIS LAI during the summer (13-20 August) of year 2017: (a) all biomes (biomes 1-8); (b) non-forest biomes (biomes 1-4); (c) broadleaf forest biomes (biomes 5-6); (d) needleleaf forest biomes (biomes 7-8).

For a more comprehensive comparison between AHI and MODIS LAI/FPAR, the latitudinal distributions at two dates (10-17 February and 13-20 August) in 2017 are presented in Figure 8, and the detailed mean and standard deviation (std.) of zonal LAI/FPAR differences are shown in Table 1. The LAI/FPAR from AHI and MODIS show consistent latitudinal distributions and coincide well at most latitude bands. There is an apparent peak in the tropics $\left(23^{\circ} \mathrm{N}-23^{\circ} \mathrm{S}\right)$, due to dense vegetation coverage in the tropical rain forests of Southeast Asia. In this latitude band $\left(23^{\circ} \mathrm{N}-23^{\circ} \mathrm{S}\right)$, the LAI/FPAR in February match well with those from August, which can be explained by ample illumination at all seasons in the tropics. The northern hemisphere shows much higher LAI/FPAR in August than in February, while there is no obvious seasonal difference in the southern hemisphere. This is because the dominant biome types in the southern hemisphere are savannas, shrubs, and grasses that have smaller seasonal variations than the forests that dominate the northern hemisphere (Figures S1, S5, and S6). Adams et al. reported that in dry and warm climates, which cannot support tree cover, the natural vegetation present is mainly open grasslands and shrublands [66]. This can explain the fact that the dominant biome types in the southern hemisphere are savannas, shrubs, and grasses. Larger LAI/FPAR differences between AHI and MODIS are observed in higher LAI/FPAR domain, which indicates that the differences depend on the LAI/FPAR magnitudes. One possible reason is that the saturation rate increases with increasing LAI [47]. Table 1 demonstrates the same seasonal and zonal patterns, for all the four latitudinal bands $\left(>45^{\circ} \mathrm{N}, 23^{\circ} \mathrm{N}-45^{\circ} \mathrm{N}, 23^{\circ} \mathrm{S}-23^{\circ} \mathrm{N}, 23^{\circ} \mathrm{S}-45^{\circ} \mathrm{S}\right)$, the LAI/FPAR differences between AHI and MODIS in August are larger than in February. Among the four zones, the latitudinal band $23^{\circ} \mathrm{N}-23^{\circ} \mathrm{S}$ has the largest LAI/FPAR differences in both February and August, with $0.130 \pm 0.431$ in February and $0.194 \pm 0.525$ in August for LAI, and $0.048 \pm 0.074$ in February and $0.061 \pm 0.079$ in August for FPAR. 
(a)

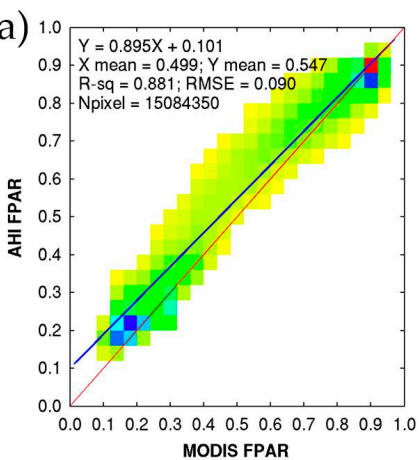

(c)

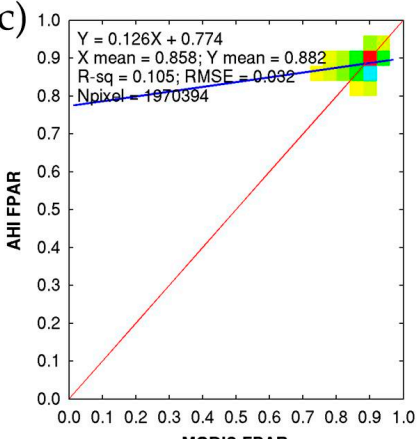

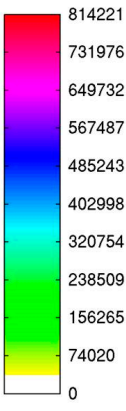

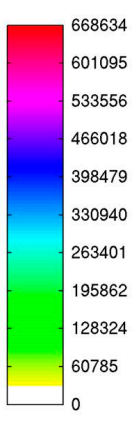

(b)
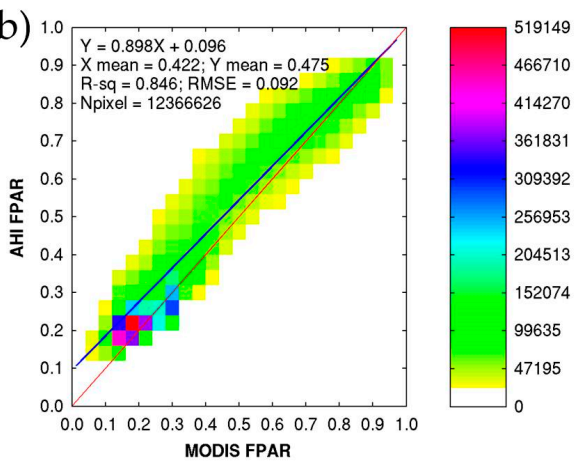

(d)
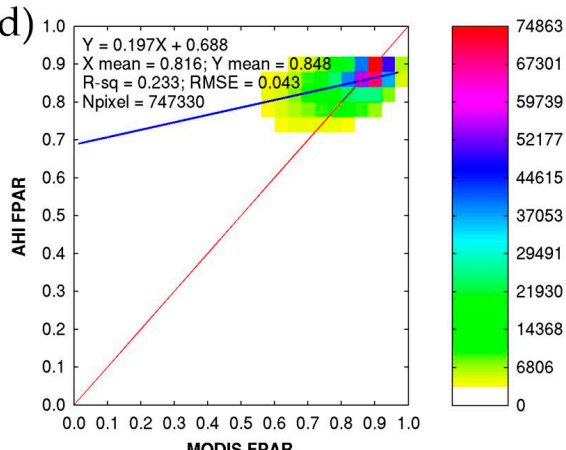

MODIS FPAR

Figure 7. Density scatter plots of biome-specific AHI and MODIS FPAR during the summer (13-20 August) of year 2017: (a) all biomes (biomes 1-8); (b) non-forest biomes (biomes 1-4); (c) broadleaf forest biomes (biomes 5-6); (d) needleleaf forest biomes (biomes 7-8).

(a)

a)

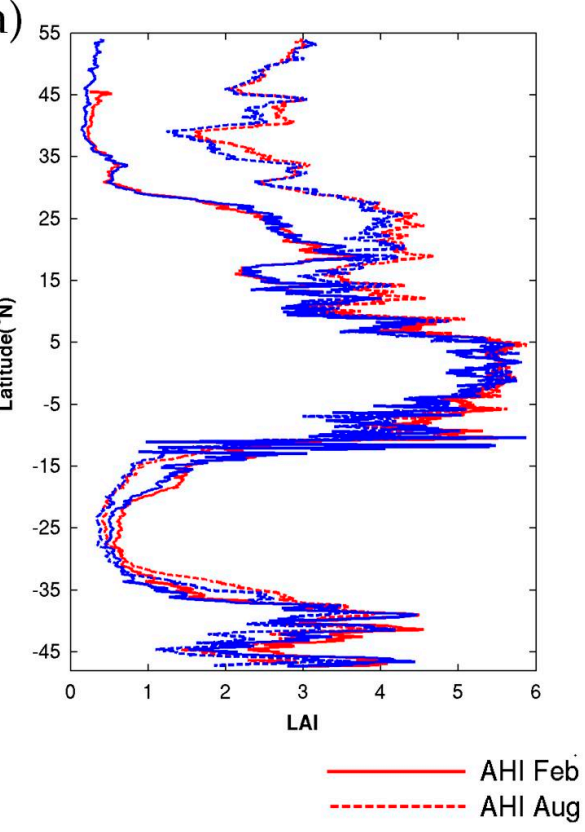

(b)

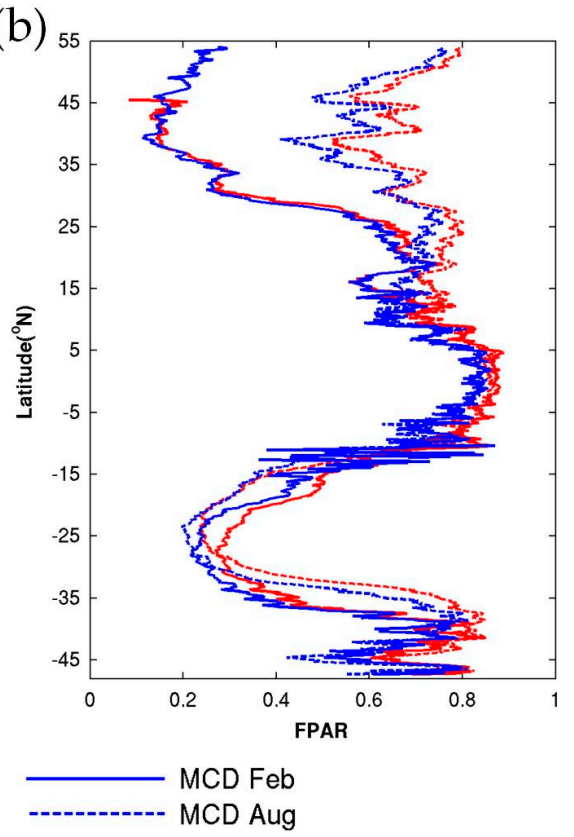

Figure 8. Latitudinal distributions of LAI and FPAR. The latitude interval is $0.1^{\circ}$. AHI and MODIS products are red and blue lines, respectively. Solid and dashed lines depict February and August in 2017: (a) LAI; (b) FPAR. 
Table 1. Mean and standard deviation of zonal differences of LAI/FPAR between AHI and MODIS.

\begin{tabular}{cccc}
\hline & & LAI & FPAR \\
\hline \multirow{2}{*}{$>45^{\circ} \mathrm{N}$} & Feb & $0.031 \pm 0.197$ & $-0.013 \pm 0.042$ \\
& Aug & $-0.191 \pm 0.856$ & $0.049 \pm 0.102$ \\
\hline \multirow{2}{*}{$23^{\circ} \mathrm{N}-45^{\circ} \mathrm{N}$} & Feb & $-0.031 \pm 0.557$ & $0.012 \pm 0.091$ \\
& Aug & $0.107 \pm 0.964$ & $0.054 \pm 0.118$ \\
\hline \multirow{2}{*}{$23^{\circ} \mathrm{S}-23^{\circ} \mathrm{N}$} & Feb & $0.017 \pm 0.726$ & $0.032 \pm 0.073$ \\
& Aug & $0.102 \pm 0.653$ & $0.025 \pm 0.083$ \\
\hline \multirow{2}{*}{$23^{\circ} \mathrm{S}-45^{\circ} \mathrm{S}$} & Feb & $0.130 \pm 0.431$ & $0.048 \pm 0.074$ \\
& Aug & $0.194 \pm 0.525$ & $0.061 \pm 0.079$ \\
\hline
\end{tabular}

\subsubsection{Temporal Consistency}

Figure 9 shows the seasonal trajectory of AHI and MODIS LAI/FPAR 4-day composite over the AHI domain during the period of 2016 to 2017. The 4-day LAI/FPAR time series of AHI and MODIS and the mean difference (the difference was first calculated in each $0.01^{\circ} \times 0.01^{\circ}$ grid, and then the mean was calculated for all grids) between them are depicted here, and the missing data rate of each 4-day composite are also provided. Figure 9 indicates that AHI provides many more cloud-free observations since its missing data rate is much lower than MODIS during the whole year. This is due to the much higher temporal resolution of AHI, which will benefit environment monitoring, climate change, etc. The time series from both sensors shows similar seasonality. In both cases, two obvious peaks in a year can be observed due to staggered seasonality in the two hemispheres. As expected, higher LAI/FPAR values (up to 1.9 for LAI and 0.53 for FPAR) appear in the boreal summer (e.g., August), while much lower LAI/FPAR values (about 1.3 for LAI and 0.39 for FPAR) are observed during boreal winter (e.g., February). This is because a larger proportion of vegetation exists in northern hemisphere. The LAI/FPAR differences between AHI and MODIS also show similar seasonal behavior with larger differences (up to 0.2 for LAI and 0.07 for FPAR) observed in high LAI/FPAR domain (e.g., boreal summer) and smaller differences (about 0.08 for LAI and 0.03 for FPAR) in low LAI/FPAR domain (e.g., boreal winter). The differences are closely related to the LAI/FPAR magnitudes, possibly due to saturation in dense forests. Figure 9 demonstrates that the LAI/FPAR from AHI and MODIS agree well with small mean differences of 0.078 for LAI and 0.038 for FPAR. The biome-specific seasonal patterns of AHI and MODIS LAI/FPAR are depicted in Figures S5 and S6. For each biome, the seasonal variations in AHI and MODIS LAI/FPAR products also agree well. The LAI/FPAR of non-forest biomes (biome 1-4) is much lower than forests (biome 5-6). Shrublands (biome 2) and evergreen broadleaf forests (biome 5) show weak seasonal LAI/FPAR variations, while deciduous broadleaf forests (biome 6) reach its peak (around 5 for LAI and 0.8 for FPAR) during boreal summer and drops to bottom (about 1 for LAI and 0.4 for FPAR) in winter. The results illustrate a high temporal consistency between AHI and MODIS LAI/FPAR products.

Table 2 details the comparison between AHI and MODIS LAI/FPAR in terms of temporal consistency at a seasonal scale for each biome type. We calculated the mean and std. of LAI/FPAR differences between AHI and MODIS for each biome type at a 3-month interval (March-May (MAM), June-August (JJA), September-November (SON), and December-February (DJF)) during 2016-2017. Although the LAI/FPAR differences between AHI and MODIS vary by biome and season, mean and std. of the differences are presented. The statistics show that the largest mean LAI/FPAR differences appear in JJA among the four seasons for most biomes, and the largest std. is observed in DJF for most biomes. This is because of the high LAI/FPAR values in JJA and growing seasons in DJF. Among all biome types, forest biomes (biomes 5-8) show larger LAI differences with much larger std. values than non-forest biomes (biomes 1-4), and the forest biomes (biomes 5-8) show underestimations of LAI (negative mean differences) due to saturation of NDVI in high domain (Figure S3). 
(a)

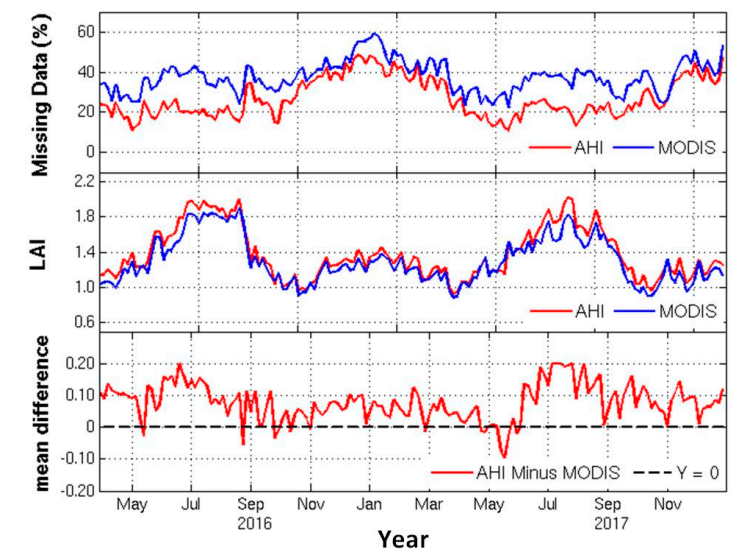

(b)

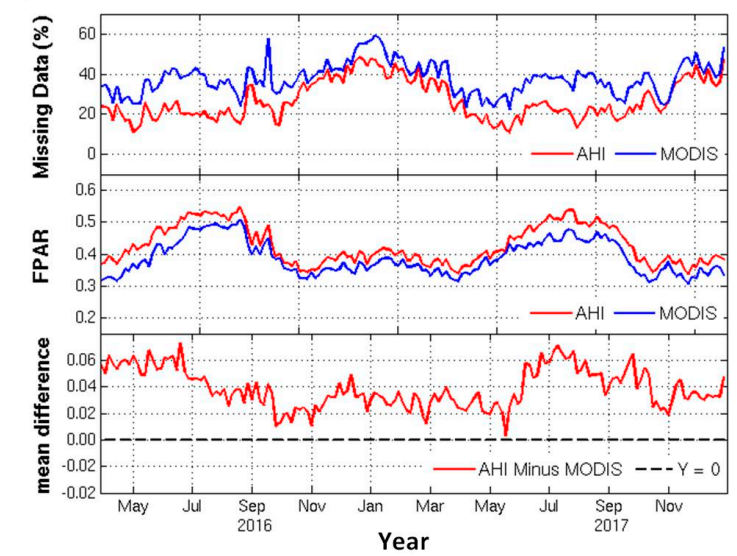

Figure 9. Temporal comparison between AHI LAI/FPAR and MODIS LAI/FPAR over the AHI domain. Global mean LAI/FPAR time series from AHI and MODIS at a 4-day interval during 2016-2017 are shown here. The top panel shows the missing data rate, while the bottom two panels show the seasonal variation of AHI and MODIS LAI/FPAR retrievals and the mean of difference between them: (a) LAI; (b) FPAR.

Table 2. Biome-specific mean and standard deviation of LAI/FPAR differences between AHI and MODIS at a seasonal scale during 2016-2017.

\begin{tabular}{ccccccccc}
\hline \multirow{2}{*}{ Biome Type } & \multicolumn{3}{c}{ LAI } & \multicolumn{4}{c}{ FPAR } \\
\cline { 2 - 9 } & MAM & JJA & SON & DJF & MAM & JJA & SON & DJF \\
\hline Biome 1 & $0.02 \pm 0.43$ & $0.06 \pm 0.36$ & $0.03 \pm 0.34$ & $0.05 \pm 0.67$ & $0.02 \pm 0.09$ & $0.02 \pm 0.08$ & $0.02 \pm 0.08$ & $0.08 \pm 0.12$ \\
\hline Biome 2 & $0.02 \pm 0.20$ & $0.04 \pm 0.15$ & $0.04 \pm 0.14$ & $0.06 \pm 0.18$ & $0.01 \pm 0.05$ & $0.03 \pm 0.06$ & $0.02 \pm 0.06$ & $0.03 \pm 0.06$ \\
\hline Biome 3 & $0.05 \pm 0.56$ & $0.06 \pm 0.49$ & $0.04 \pm 0.52$ & $0.13 \pm 0.77$ & $0.03 \pm 0.09$ & $0.02 \pm 0.09$ & $0.03 \pm 0.09$ & $0.06 \pm 0.10$ \\
\hline Biome 4 & $0.06 \pm 0.66$ & $0.11 \pm 0.65$ & $0.01 \pm 0.66$ & $0.03 \pm 0.72$ & $0.03 \pm 0.09$ & $0.03 \pm 0.09$ & $0.02 \pm 0.10$ & $0.02 \pm 0.09$ \\
\hline Biome 5 & $0.14 \pm 1.19$ & $-0.22 \pm 1.14$ & $-0.10 \pm 1.28$ & $0.14 \pm 1.22$ & $0.05 \pm 0.09$ & $0.06 \pm 0.09$ & $0.04 \pm 0.10$ & $0.05 \pm 0.10$ \\
\hline Biome 6 & $-0.04 \pm 0.85$ & $0.17 \pm 0.49$ & $-0.06 \pm 0.82$ & $0.02 \pm 1.12$ & $0.04 \pm 0.11$ & $0.04 \pm 0.10$ & $0.03 \pm 0.10$ & $0.03 \pm 0.09$ \\
\hline Biome 7 & $0.07 \pm 0.94$ & $-0.05 \pm 0.96$ & $-0.07 \pm 0.83$ & $0.07 \pm 1.21$ & $0.04 \pm 0.13$ & $0.04 \pm 0.15$ & $0.03 \pm 0.13$ & $0.05 \pm 0.12$ \\
\hline Biome 8 & $-0.10 \pm 0.56$ & $0.27 \pm 0.78$ & $-0.04 \pm 0.45$ & $0.03 \pm 1.12$ & $0.03 \pm 0.09$ & $0.10 \pm 0.16$ & $0.03 \pm 0.09$ & $0.03 \pm 0.10$ \\
\hline
\end{tabular}

The "MAM", "JJA", "SON", and "SON" stand for "March-May", "June-August", "September-November", and "December-February", respectively.

\subsection{Validation with Field Measurements}

The uncertainty of both AHI and MODIS LAI products was evaluated using ground measurements, as shown in Figure 10. There are no field measurements available over the AHI domain during 2016-2017. Therefore, we used the MODIS LAI in 2012-2013 and 2016-2017 as the intermediary between AHI LAI in 2016-2017 and the latest available field measurements in 2012-2013 LAI to address the time inconsistency issue. The MODIS LAI products were validated with the field measured LAI during 2012-2013, and then, the AHI LAI products were compared to the MODIS products in the same field sites during the same period of 2016-2017. For each site, the mean values of AHI and MODIS LAI over a $3 \mathrm{~km} \times 3 \mathrm{~km}$ area were used to compare with field measurements or between the two products. Table S1 describes the characteristics of the available ground sites and aggregated LAI. 
(a)

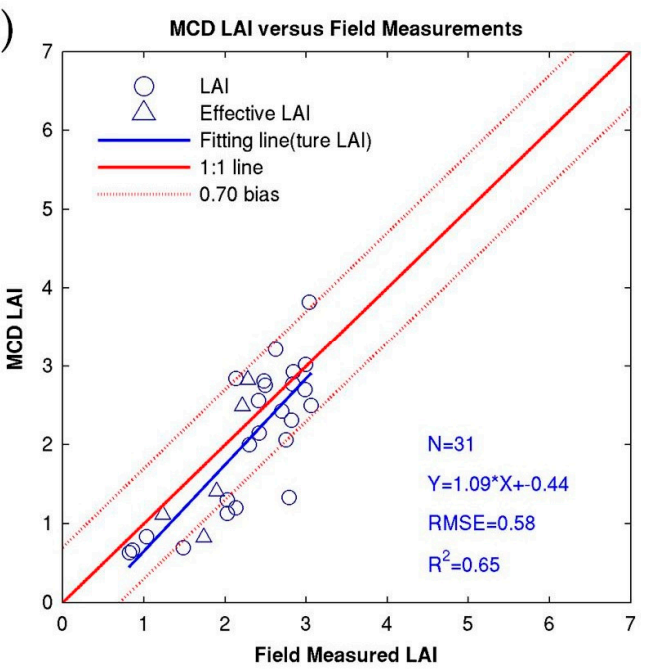

(b)

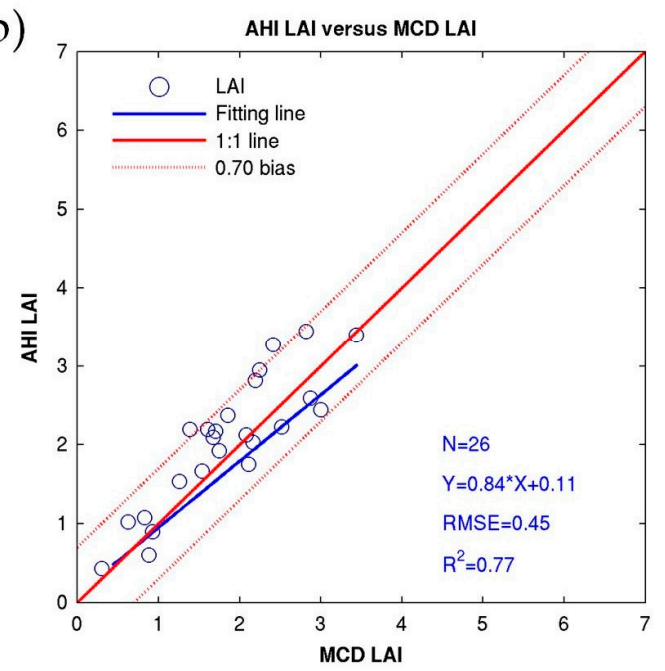

Figure 10. Comparison between field measurements and LAI products: (a) MCD LAI versus field measured LAI (2012-2013); (b) AHI LAI versus MCD LAI (2016-2017).

Figure 10a shows the degree of agreement between the MODIS LAI and field measured LAI ( $R^{2}$ of 0.65 and RMSE of 0.58 ). Most of the data are located within \pm 0.7 LAI bias, indicating that the uncertainty of MODIS LAI at the field sites is less than \pm 0.7 LAI. A better agreement between AHI and MODIS LAI can be observed from Figure $10 \mathrm{~b}$ ( $\mathrm{R}^{2}$ of 0.77 and RMSE of 0.45 ), indicating that the AHI LAI match well with MODIS LAI. These results in Figure 10 indirectly demonstrate that the uncertainty of AHI LAI is within a small range. A larger inconsistency between AHI and MODIS LAI appears in high LAI domains, which agrees with the conclusions from Section 4.2.

\subsection{Evaluation of Phenology}

We selected four sites to evaluate the potential of AHI LAI/FPAR to capture phenology in comparison to MODIS products (one for grasses and cereal crops, one for broadleaf crops, and two for deciduous broadleaf forests). Figure 10 shows the evaluation results of phenology. There are more gaps in MOD EVI and MOD NDVI because MOD data are observations only from Terra MODIS while MCD data are Terra and Aqua combined. For each site, the AHI LAI/FPAR shows the same phenological development as MODIS products because the AHI LAI/FPAR lines agree well with MODIS LAI/FPAR, NDVI, and EVI lines. The two deciduous broadleaf forest sites show very similar pattern with an obvious peak during 100-300 of 2017 (Figure 11c,d), which is the growing season. As expected, the deciduous broadleaf forest (about 200 days) have much longer growing season than grasses and cereal crops (about 100 days) and broadleaf crops (about 125 days). The results indicate the ability of AHI LAI/FPAR to monitor vegetation phenological change. 
(a)

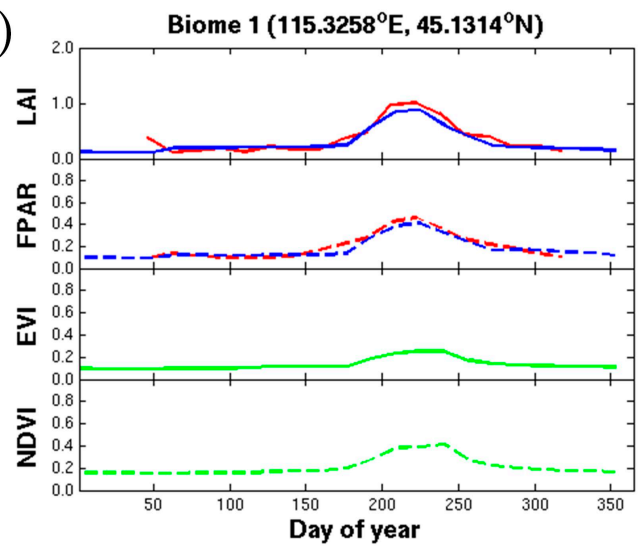

(c)

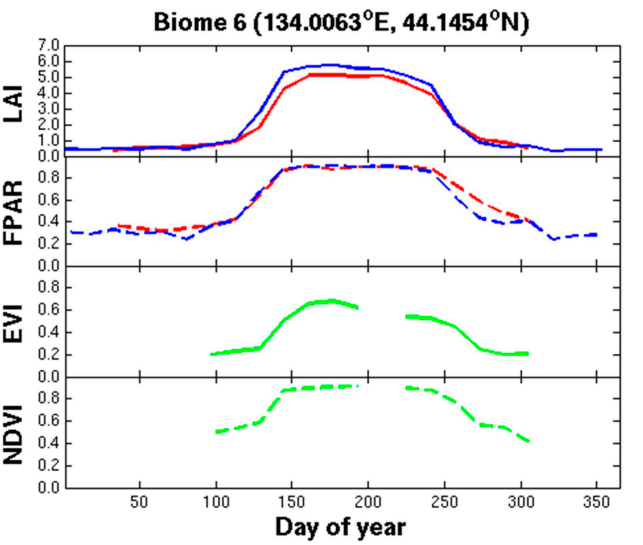

(b)

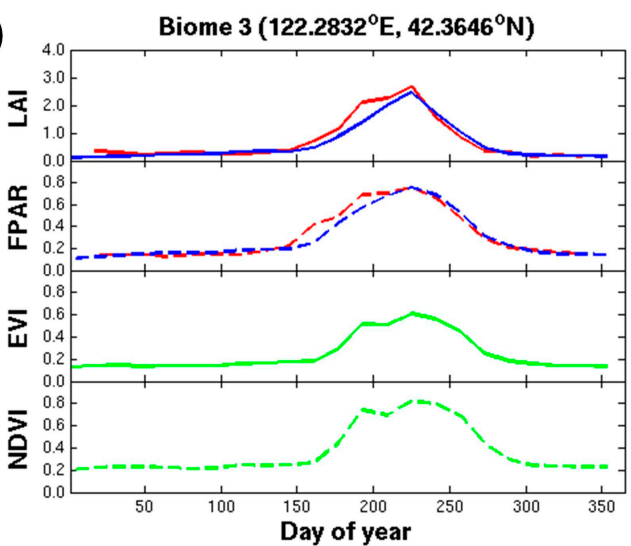

(d)

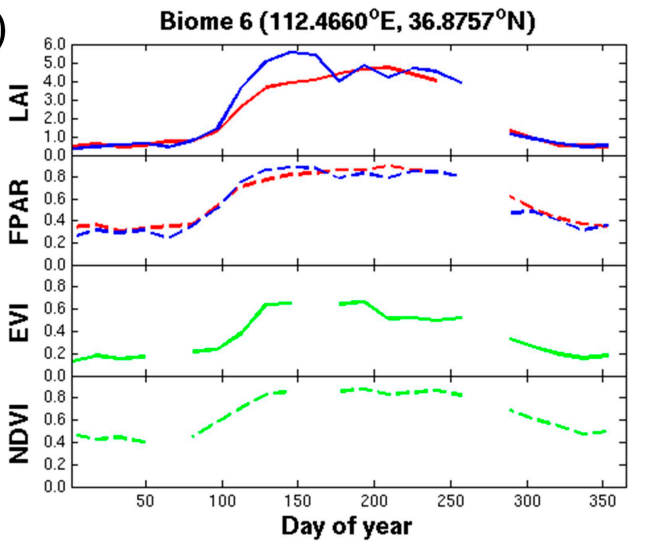

- AHI LAI —MCD LAI ---AHI FPAR ---MCD FPAR —MOD EVI ---MOD NDVI

Figure 11. Phenology of four sites in 2017. The upper two panels show phenological development from LAI and FPAR products and the following two panels show that from enhanced vegetation index (EVI) and NDVI products: (a) Biome 1: grasses and cereal crops $\left(115.3258^{\circ} \mathrm{E}, 45.1314^{\circ} \mathrm{N}\right)$; (b) biome 3: broadleaf crops $\left(122.2832^{\circ} \mathrm{E}, 42.3646^{\circ} \mathrm{N}\right)$; (c) biome 6: deciduous broadleaf forests $\left(134.0063^{\circ} \mathrm{E}, 44.1454^{\circ} \mathrm{N}\right)$; (d) biome 6: deciduous broadleaf forest $\left(112.4660^{\circ} \mathrm{E}, 36.8757^{\circ} \mathrm{N}\right)$.

\section{Conclusions}

Most of the existing LAI/FPAR products are generated from non-geostationary satellite observations. The products generated from such data are not spatially and temporally continuous due to relative long revisit times and cloud- and cloud-shadow contamination. Fortunately, the AHI onboard geostationary satellite Himawari-8 provides observations of the Earth surface at a 10-min or even higher temporal frequency. The up-to-minute remote sensing data can be composited to minimize such contamination, and this can generate products that can contribute to the numerical weather prediction, disaster and environmental monitoring. The purpose of this study was to generate Himawari-8 AHI LAI/FPAR products for effective use in most global models of climate, biochemistry, and ecology, and to evaluate the AHI LAI/FPAR products with reference to the MODIS LAI/FPAR products.

We utilized ANNs in a simple and efficient approach to estimate the AHI LAI/FPAR. Several comparisons between the AHI and MODIS products indicate good agreement and overall consistency between them. Specifically, the estimated LAI/FPAR from AHI agrees well with those from MODIS in terms of both spatial and temporal scales. Further, validation with ground truth data shows acceptable uncertainty in the derived AHI products. Additionally, we also evaluated the AHI LAI/FPAR products for their potential to accurately monitor vegetation phenology, and our results show that AHI LAI/FPAR products capture the phenological development in a manner similar to the MODIS products.

The validation of AHI LAI product uncertainty in this study is limited by the availability of ground measurements. More spatially and temporally well-distributed field measurements are required to 
perform comprehensive and robust validation. The comparison between AHI and MODIS products shows large differences in high LAI/FPAR domain and the results in our study show overestimation of FPAR. Future work should therefore focus on optimizing the main MODIS algorithm, i.e., the one based on radiative transfer theory, for retrieval of AHI LAI/FPAR fields, with the ANNs constituting the back-up algorithm.

Supplementary Materials: The following are available online at http://www.mdpi.com/2072-4292/11/13/1517/s1, Figure S1: Biome map used in this study. Figure S2: The quality control based on "FparLai_QC" and "FparExtra_QC" layers for MODIS LAI/FPAR products. Figure S3: The relationship between NDVI and LAI/FPAR. Figure S4: Comparison of seasonal variations in LAI between AHI and MODIS over AHI domain for each biome type during 2017. Figure S5: Comparison of seasonal variations in FPAR between AHI and MODIS over AHI domain for each biome type during 2017. Table S1: Characteristics of the available ground sites and aggregated LAI_effective/LAI_true values over a $3 \mathrm{~km} \times 3 \mathrm{~km}$ area.

Author Contributions: Y.C., K.C., C.C., W.W., R.R.N., and R.B.M. conceived and designed the experiments; Y.C. and C.C. performed the experiments; Y.C., T.B., and T.P. discussed the results. All authors contributed to the writing of the paper.

Funding: This work was partially funded by the National Key Research and Development Program of China (NO. 2016YFB0502600) and the National Natural Science Foundation of China (NO. 41471354). Funds from NASA $\mathrm{HQ}$ to the GeoNEX project exploring geostationary satellite data for land monitoring supported part of this work.

Acknowledgments: Yepei Chen would like to thank the China Scholarship Council for the scholarship.

Conflicts of Interest: The authors declare no conflict of interest.

\section{References}

1. Chen, J.M.; Black, T. Defining leaf area index for non-flat leaves. Plant Cell Environ. 1992, 15, 421-429. [CrossRef]

2. Myneni, R.B.; Ramakrishna, R.; Nemani, R.; Running, S.W. Estimation of global leaf area index and absorbed par using radiative transfer models. IEEE Trans. Geosci. Remote Sens. 1997, 35, 1380-1393. [CrossRef]

3. Garrigues, S.; Lacaze, R.; Baret, F.; Morisette, J.; Weiss, M.; Nickeson, J.; Fernandes, R.; Plummer, S.; Shabanov, N.; Myneni, R. Validation and intercomparison of global leaf area index products derived from remote sensing data. J. Geophys. Res. Biogeosci. 2008, 113. [CrossRef]

4. Chen, J.M. Canopy architecture and remote sensing of the fraction of photosynthetically active radiation absorbed by boreal conifer forests. IEEE Trans. Geosci. Remote Sens. 1996, 34, 1353-1368. [CrossRef]

5. Fensholt, R.; Sandholt, I.; Rasmussen, M.S. Evaluation of modis lai, fapar and the relation between fapar and ndvi in a semi-arid environment using in situ measurements. Remote Sens. Environ. 2004, 91, 490-507. [CrossRef]

6. Sellers, P.; Dickinson, R.; Randall, D.; Betts, A.; Hall, F.; Berry, J.; Collatz, G.; Denning, A.; Mooney, H.; Nobre, $\mathrm{C}$. Modeling the exchanges of energy, water, and carbon between continents and the atmosphere. Science 1997, 275, 502-509. [CrossRef]

7. Knorr, W.; Kattge, J. Inversion of terrestrial ecosystem model parameter values against eddy covariance measurements by monte carlo sampling. Glob. Chang. Biol. 2005, 11, 1333-1351. [CrossRef]

8. Richardson, A.D.; Anderson, R.S.; Arain, M.A.; Barr, A.G.; Bohrer, G.; Chen, G.; Chen, J.M.; Ciais, P.; Davis, K.J. Terrestrial biosphere models need better representation of vegetation phenology: Results from the north american carbon program site synthesis. Glob. Chang. Biol. 2012, 18, 566-584. [CrossRef]

9. Winkler, A.J.; Myneni, R.B.; Alexandrov, G.A.; Brovkin, V. Earth system models underestimate carbon fixation by plants in the high latitudes. Nat. Commun. 2019, 10, 885. [CrossRef]

10. Myneni, R.B.; Hoffman, S.; Knyazikhin, Y.; Privette, J.; Glassy, J.; Tian, Y.; Wang, Y.; Song, X.; Zhang, Y.; Smith, G. Global products of vegetation leaf area and fraction absorbed par from year one of modis data. Remote Sens. Environ. 2002, 83, 214-231. [CrossRef]

11. Xiao, Z.; Liang, S.; Sun, R.; Wang, J.; Jiang, B. Estimating the fraction of absorbed photosynthetically active radiation from the modis data based glass leaf area index product. Remote Sens. Environ. 2015, 171, 105-117. [CrossRef] 
12. Chen, C.; Knyazikhin, Y.; Park, T.; Yan, K.; Lyapustin, A.; Wang, Y.; Yang, B.; Myneni, R. Prototyping of lai and fpar retrievals from modis multi-angle implementation of atmospheric correction (maiac) data. Remote Sens. 2017, 9, 370. [CrossRef]

13. Xiao, Z.; Liang, S.; Wang, T.; Jiang, B. Retrieval of leaf area index (lai) and fraction of absorbed photosynthetically active radiation (fapar) from viirs time-series data. Remote Sens. 2016, 8, 351. [CrossRef]

14. Yan, K.; Park, T.; Chen, C.; Xu, B.; Song, W.; Yang, B.; Zeng, Y.; Liu, Z.; Yan, G.; Knyazikhin, Y. Generating global products of lai and fpar from snpp-viirs data: Theoretical background and implementation. IEEE Trans. Geosci. Remote Sens. 2018, 56, 2119-2137. [CrossRef]

15. Ma, H.; Liang, S.; Xiao, Z.; Wang, D. Simultaneous estimation of multiple land-surface parameters from viirs optical-thermal data. IEEE Geosci. Remote Sens. Lett. 2018, 15, 156-160. [CrossRef]

16. Baret, F.; Hagolle, O.; Geiger, B.; Bicheron, P.; Miras, B.; Huc, M.; Berthelot, B.; Niño, F.; Weiss, M.; Samain, O.; et al. Lai, fapar and fcover cyclopes global products derived from vegetation: Part 1: Principles of the algorithm. Remote Sens. Environ. 2007, 110, 275-286. [CrossRef]

17. Baret, F.; Weiss, M.; Lacaze, R.; Camacho, F.; Makhmara, H.; Pacholcyzk, P.; Smets, B. Geov1: Lai and fapar essential climate variables and fover global time series capitalizing over existing products. Part1: Principles of development and production. Remote Sens. Environ. 2013, 137, 299-309. [CrossRef]

18. Verger, A.; Baret, F.; Weiss, M.; Filella, I.; Peñuelas, J. Geoclim: A global climatology of lai, fapar, and fcover from vegetation observations for 1999-2010. Remote Sens. Environ. 2015, 166, 126-137. [CrossRef]

19. Vinué Visús, D.; Camacho de Coca, F.; Fuster, B. Validation of sentinel-2 lai and fapar products derived from snap toolbox over the barrax cropland site (spain). In Proceedings of the 5th International Symposium on Recent Advances in Quantitative Remote Sensing, Valencia, Spain, 18-22 September 2017.

20. Vuolo, F.; Żółtak, M.; Pipitone, C.; Zappa, L.; Wenng, H.; Immitzer, M.; Weiss, M.; Baret, F.; Atzberger, C. Data service platform for sentinel-2 surface reflectance and value-added products: System use and examples. Remote Sens. 2016, 8, 938. [CrossRef]

21. Li, W.; Weiss, M.; Waldner, F.; Defourny, P.; Demarez, V.; Morin, D.; Hagolle, O.; Baret, F. A generic algorithm to estimate lai, fapar and fcover variables from spot4_hrvir and landsat sensors: Evaluation of the consistency and comparison with ground measurements. Remote Sens. 2015, 7, 15494-15516. [CrossRef]

22. Zhao, J.; Li, J.; Liu, Q.; Fan, W.; Zhong, B.; Wu, S.; Yang, L.; Zeng, Y.; Xu, B.; Yin, G. Leaf area index retrieval combining hj1/ccd and landsat8/oli data in the heihe river basin, China. Remote Sens. 2015, 7, 6862-6885. [CrossRef]

23. Ovakoglou, G.; Alexandridis, T.K.; Clevers, J.G.; Cherif, I.; Kasampalis, D.A.; Navrozidis, I.; Iordanidis, C.; Moshou, D.; Laneve, G.; Beltran, J.S. Spatial enhancement of modis leaf area index using regression analysis with landsat vegetation index. In Proceedings of the IGARSS 2018-2018 IEEE International Geoscience and Remote Sensing Symposium, Valencia, Spain, 22-27 July 2018; IEEE: Piscataway, NJ, USA, 2018; pp. 8232-8235.

24. Zhou, J.; Zhang, S.; Yang, H.; Xiao, Z.; Gao, F. The retrieval of 30-m resolution lai from landsat data by combining modis products. Remote Sens. 2018, 10, 1187. [CrossRef]

25. Houborg, R.; McCabe, M.F.; Gao, F. A spatio-temporal enhancement method for medium resolution lai (stem-lai). Int. J. Appl. Earth Obs. Geoinf. 2016, 47, 15-29. [CrossRef]

26. Da, C. Preliminary assessment of the advanced himawari imager (ahi) measurement onboard himawari-8 geostationary satellite. Remote Sens. Lett. 2015, 6, 637-646. [CrossRef]

27. Bessho, K.; Date, K.; Hayashi, M.; Ikeda, A.; Imai, T.; Inoue, H.; Kumagai, Y.; Miyakawa, T.; Murata, H.; Ohno, T.; et al. An introduction to himawari-8/9-Japan's new-generation geostationary meteorological satellites. J. Meteorol. Soc. Jpn. 2016, 94, 151-183. [CrossRef]

28. Yu, F.; Wu, X. Radiometric inter-calibration between himawari-8 ahi and s-npp viirs for the solar reflective bands. Remote Sens. 2016, 8, 165. [CrossRef]

29. Claverie, M.; Matthews, J.L.; Vermote, E.F.; Justice, C.O. A 30+ year avhrr lai and fapar climate data record: Algorithm description and validation. Remote Sens. 2016, 8, 263. [CrossRef]

30. Zhu, Z.; Bi, J.; Pan, Y.; Ganguly, S.; Anav, A.; Xu, L.; Samanta, A.; Piao, S.; Nemani, R.; Myneni, R. Global data sets of vegetation leaf area index (lai) $3 \mathrm{~g}$ and fraction of photosynthetically active radiation (fpar) $3 \mathrm{~g}$ derived from global inventory modeling and mapping studies (gimms) normalized difference vegetation index (ndvi3g) for the period 1981 to 2011. Remote Sens. 2013, 5, 927-948. [CrossRef] 
31. Okuyama, A.; Andou, A.; Date, K.; Hoasaka, K.; Mori, N.; Murata, H.; Tabata, T.; Takahashi, M.; Yoshino, R.; Bessho, K. Preliminary Validation of Himawari-8/ahi Navigation and Calibration; Earth Observing Systems XXP; International Society for Optics and Photonics: Bellingham, WA, USA, 2015; p. 96072E.

32. Okuyama, A.; Takahashi, M.; Date, K.; Hosaka, K.; Murata, H.; Tabata, T.; Yoshino, R. Validation of himawari-8/ahi radiometric calibration based on two years of in-orbit data. J. Meteorol. Soc. Jpn. Ser. II 2018, 96, 91-109. [CrossRef]

33. Lyapustin, A.; Martonchik, J.; Wang, Y.; Laszlo, I.; Korkin, S. Multiangle implementation of atmospheric correction (maiac): 1. Radiative transfer basis and look-up tables. J. Geophys. Res. Atmos. 2011, 116. [CrossRef]

34. Lyapustin, A.I.; Wang, Y.; Laszlo, I.; Hilker, T.; Hall, F.G.; Sellers, P.J.; Tucker, C.J.; Korkin, S.V. Multi-angle implementation of atmospheric correction for modis (maiac): 3. Atmospheric correction. Remote Sens. Environ. 2012, 127, 385-393. [CrossRef]

35. Lyapustin, A.; Wang, Y.; Korkin, S.; Huang, D. Modis collection 6 maiac algorithm. Atmos. Meas. Tech. 2018, 11, 5741-5765. [CrossRef]

36. Badgley, G.; Field, C.B.; Berry, J.A. Canopy near-infrared reflectance and terrestrial photosynthesis. Sci. Adv. 2017, 3, e1602244. [CrossRef] [PubMed]

37. Friedl, M.; Sulla-Menashe, D. MCD12Q1 MODIS/Terra+Aqua Land Cover Type Yearly L3 Global 500m SIN Grid V006. NASA EOSDIS Land Processes DAAC. Available online: https://pdaac.usgs.gov/products/ mcd12q1v006/ (accessed on 26 June 2019).

38. Ahl, D.E.; Gower, S.T.; Burrows, S.N.; Shabanov, N.V.; Myneni, R.B.; Knyazikhin, Y. Monitoring spring canopy phenology of a deciduous broadleaf forest using modis. Remote Sens. Environ. 2006, 104, 88-95. [CrossRef]

39. Narasimhan, R.; Stow, D. Daily modis products for analyzing early season vegetation dynamics across the north slope of alaska. Remote Sens. Environ. 2010, 114, 1251-1262. [CrossRef]

40. Bi, J.; Myneni, R.; Lyapustin, A.; Wang, Y.; Park, T.; Chi, C.; Yan, K.; Knyazikhin, Y. Amazon forests' response to droughts: A perspective from the maiac product. Remote Sens. 2016, 8, 356. [CrossRef]

41. Chen, C.; Park, T.; Wang, X.; Piao, S.; Xu, B.; Chaturvedi, R.K.; Fuchs, R.; Brovkin, V.; Ciais, P.; Fensholt, R. China and india lead in greening of the world through land-use management. Nat. Sustain. 2019, 2, 122. [CrossRef] [PubMed]

42. Zhou, Q.; Fellows, A.; Flerchinger, G.N.; Flores, A.N. Examining interactions between and among predictors of net ecosystem exchange: A machine learning approach in a semi-arid landscape. Sci. Rep. 2019, 9, 2222. [CrossRef]

43. Tian, Y.; Woodcock, C.E.; Wang, Y.; Privette, J.L.; Shabanov, N.V.; Zhou, L.; Zhang, Y.; Buermann, W.; Dong, J.; Veikkanen, B. Multiscale analysis and validation of the modis lai product: I. Uncertainty assessment. Remote Sens. Environ. 2002, 83, 414-430. [CrossRef]

44. Serbin, S.P.; Ahl, D.E.; Gower, S.T. Spatial and temporal validation of the modis lai and fpar products across a boreal forest wildfire chronosequence. Remote Sens. Environ. 2013, 133, 71-84. [CrossRef]

45. Yan, K.; Park, T.; Yan, G.; Chen, C.; Yang, B.; Liu, Z.; Nemani, R.; Knyazikhin, Y.; Myneni, R. Evaluation of modis lai/fpar product collection 6. Part 1: Consistency and improvements. Remote Sens. 2016, 8, 359. [CrossRef]

46. Yan, K.; Park, T.; Yan, G.; Liu, Z.; Yang, B.; Chen, C.; Nemani, R.; Knyazikhin, Y.; Myneni, R. Evaluation of modis lai/fpar product collection 6. Part 2: Validation and intercomparison. Remote Sens. 2016, 8, 460. [CrossRef]

47. Xu, B.; Park, T.; Yan, K.; Chen, C.; Zeng, Y.; Song, W.; Yin, G.; Li, J.; Liu, Q.; Knyazikhin, Y.; et al. Analysis of global lai/fpar products from viirs and modis sensors for spatio-temporal consistency and uncertainty from 2012-2016. Forests 2018, 9, 73. [CrossRef]

48. Li, X.; Lu, H.; Yu, L.; Yang, K. Comparison of the spatial characteristics of four remotely sensed leaf area index products over china: Direct validation and relative uncertainties. Remote Sens. 2018, 10, 148. [CrossRef]

49. Myneni, R.; Knyazikhin, Y.; Park, T. MCD15A3H MODIS/Terra+Aqua Leaf Area Index/FPAR 4-Day L4 Global 500m SIN Grid V006. NASA EOSDIS Land Processes DAAC. Available online: https:/catalog. data.gov/dataset/modis-terraaqua-leaf-area-index-fpar-4-day-14-global-500m-sin-grid-v006 (accessed on 26 June 2019). 
50. Didan, K. MOD13A2 MODIS/Terra Vegetation Indices 16-Day L3 Global 1 km SIN Grid V006. NASA EOSDIS Land Processes DAAC. Available online: https://lpdaac.usgs.gov/products/mod13a2v006/ (accessed on 26 June 2019).

51. Camacho, F.; Lacaze, R.; Latorre, C.; Baret, F.; De la Cruz, F.; Demarez, V.; Di Bella, C.; García-Haro, J.; González-Dugo, M.P.; Kussul, N.; et al. Collection of ground biophysical measurements in support of copernicus global land product validation: The imagines database. In Proceedings of the EGU General Assembly, Vienna, Austria, 17-22 April 2015; Geophysical Research Abstracts, 17 EGU2015-2209-1. Available online: http://adsabs.harvard.edu/abs/2015EGUGA..17.2209C (accessed on 26 June 2019).

52. Zeng, Y.; Li, J.; Liu, Q.; Qu, Y.; Huete, A.; Xu, B.; Yin, G.; Zhao, J. An optimal sampling design for observing and validating long-term leaf area index with temporal variations in spatial heterogeneities. Remote Sens. 2015, 7, 1300-1319. [CrossRef]

53. Morisette, J.T.; Baret, F.; Privette, J.L.; Myneni, R.B.; Nickeson, J.E.; Garrigues, S.; Shabanov, N.V.; Weiss, M.; Fernandes, R.A.; Leblanc, S.G. Validation of global moderate-resolution lai products: A framework proposed within the ceos land product validation subgroup. IEEE Trans. Geosci. Remote Sens. 2006, 44, 1804-1817. [CrossRef]

54. Li, X.; Cheng, G.; Liu, S.; Xiao, Q.; Ma, M.; Jin, R.; Che, T.; Liu, Q.; Wang, W.; Qi, Y. Heihe watershed allied telemetry experimental research (hiwater): Scientific objectives and experimental design. Bull. Am. Meteorol. Soc. 2013, 94, 1145-1160. [CrossRef]

55. Myneni, R.B.; Hall, F.G.; Sellers, P.J.; Marshak, A.L. The interpretation of spectral vegetation indexes. IEEE Trans. Geosci. Remote Sens. 1995, 33, 481-486. [CrossRef]

56. Colombo, R.; Bellingeri, D.; Fasolini, D.; Marino, C.M. Retrieval of leaf area index in different vegetation types using high resolution satellite data. Remote Sens. Environ. 2003, 86, 120-131. [CrossRef]

57. Wang, Q.; Adiku, S.; Tenhunen, J.; Granier, A. On the relationship of ndvi with leaf area index in a deciduous forest site. Remote Sens. Environ. 2005, 94, 244-255. [CrossRef]

58. Alexandridis, T.K.; Ovakoglou, G.; Clevers, J.G. Relationship between modis evi and lai across time and space. Geocarto Int. 2019, 1-15. [CrossRef]

59. Houborg, R.; Soegaard, H.; Boegh, E. Combining vegetation index and model inversion methods for the extraction of key vegetation biophysical parameters using terra and aqua modis reflectance data. Remote Sens. Environ. 2007, 106, 39-58. [CrossRef]

60. Verger, A.; Baret, F.; Weiss, M. Performances of neural networks for deriving lai estimates from existing cyclopes and modis products. Remote Sens. Environ. 2008, 112, 2789-2803. [CrossRef]

61. Heermann, P.D.; Khazenie, N. Classification of multispectral remote sensing data using a back-propagation neural network. IEEE Trans. Geosci. Remote Sens. 1992, 30, 81-88. [CrossRef]

62. Kaishan, S.; Shuwen, N. Soybean lai estimation with in-situ collected hyperspectral data based on bp-neural networks. In Proceedings of the 2007 3rd International Conference on Recent Advances in Space Technologies, Istanbul, Turkey, 14-16 June 2007; IEEE: Piscataway, NJ, USA, 2007; pp. 331-336.

63. Weiss, M.; Baret, F.; Garrigues, S.; Lacaze, R. Lai and fapar cyclopes global products derived from vegetation. Part 2: Validation and comparison with modis collection 4 products. Remote Sens. Environ. 2007, 110, 317-331. [CrossRef]

64. Birky, A.K. Ndvi and a simple model of deciduous forest seasonal dynamics. Ecol. Model. 2001, 143, 43-58. [CrossRef]

65. Lüdeke, M.; Janecek, A.; Kohlmaier, G.H. Modelling the seasonal co2 uptake by land vegetation using the global vegetation index. Tellus B 1991, 43, 188-196. [CrossRef]

66. Adams, J. Vegetation-Climate Interaction: How Plants Make the Global Environment; Springer Science \& Business Media: Berlin/Heidelberg, Germany, 2009.

(C) 2019 by the authors. Licensee MDPI, Basel, Switzerland. This article is an open access article distributed under the terms and conditions of the Creative Commons Attribution (CC BY) license (http://creativecommons.org/licenses/by/4.0/). 